\title{
Ensaios sobre a cegueira: Charles Baudelaire, Pieter Bruegel, H.G.Wells e José Saramago
}

Les Aveugles

Contemple-les, mon-âme; ils sont vraiment affreux!

Pareils aux mannequins, vaguement ridicules; Terribles, singuliers comme les sonnambules; Dardant on ne sait où leurs globes ténébreux.

Leurs yeux, d'où la divine étincelle est partie, Comme s'ils regardaient au loin, restent levés Au ciel; on ne les voit jamais vers les pavés Pencher rêveusement leur tête appesantie.
Ils traversent ainsi le noir illimité, Ce frère du silence eternel. O cité! Pendant qu'autour de nous tu chantes, ris et beugles,

Éprise du plaisir jusqu'à l'atrocité,

Vois! je me trâine aussi! Mais, plus qu'eux hébété

Je dis: Que cherchent-ils au Ciel, tous ces aveugles?

Charles Baudelaire

\footnotetext{
* Doutora em Letras pela PUC-Rio, professora da Universidade Federal de Pernambuco e autora do livro $A$ mensagem e a imagem: literatura e pintura no primeiro modernismo português.
} 
A clássica relação que se estabeleceu ao longo do tempo entre literatura e pintura na história da arte criou uma tal situação de reciprocidade entre os meios de expressão que se torna freqüente, sobretudo em certas épocas, a existência de poemas inspirados em quadros e pinturas criadas a partir de textos, histórias e mesmo ditos populares. O soneto de Baudelaire em epígrafe parece seguir este princípio, evocando o quadro de Pieter Bruegel, o Velho, intitulado A parábola dos cegos, de 1568.

Em seu livro Mémoires d'aveugle, Jacques Derrida defende a hipótese de que o poema teria sido escrito a partir da tela de Bruegel:

On a proposé deux références au poème Les aveugles. [...] La première concerne une gravure ou une lithographie d'après la toile de Bruegel l'Ancien (La parabole des aveugles du Musée de Naples dont le Louvre aurait acquis une copie en 1893).

Lucia Vaina-Pusca, por sua vez, explora o tema num ensaio: "La théorie des mondes possibles dans l'étude des textes - Baudelaire lecteur de Bruegel", referindo-se ao livro Knowledge and belief, de Jaakko Hintikka, para mostrar que o poema Les aveugles inspira-se no quadro mencionado. A considerar a opinião da crítica, é provável que Baudelaire de fato tivesse em mente aquela pintura quando concebeu o seu poema.

Que Baudelaire tenha partido de uma inspiração plástica para a criação literária não surpreende, considerando o estreito vínculo existente entre o poeta de As flores do mal e a pintura, seja como apreciador, seja como crítico de arte. Toda a concepção da modernidade que aflora em seus textos, e que tanta influência exerceu sobre os modernismos que vieram depois, parece resultar de uma longa e dedicada reflexão sobre a imagem, tendo como ponto de partida os quadros e os artistas plásticos. O que intriga, na verdade, é que, apesar de tal relação, o poeta tenha selecionado justamente a temática da cegueira para trabalhar um texto construído a partir de um quadro, de uma imagem visual.

É certo que este quadro guarda as suas próprias peculiaridades, na medida em que também nasce de um outro meio - um 
texto da Bíblia, no qual Cristo critica os fariseus: "Deixai-os. São cegos e guias de cegos. Ora, se um cego conduz a outro, tombarão ambos na mesma vala". Se analisada alegoricamente, a pintura feita de modo a ilustrar esta passagem deixa clara a moral da história: a crítica aos profetas, cegos porque falsos, que se fazem de guias; e a crítica às multidões, cegas porque crédulas, que se deixam por eles conduzir aos tropeços.

De fato, Bruegel caracterizou-se como um pintor de provérbios. É famoso o seu quadro Provérbios flamengos, onde inventaria e retrata exaustivamente os ditos populares de sua época, inclusive o do "cego guiando cegos", tema que mais tarde desenvolveria à parte no quadro mencionado. O ponto de vista usado nos Provérbios, no entanto, difere do usado na Parábola. No primeiro, o pintor se coloca numa posição elevada, de modo a oferecer ao observador uma perspectiva quase onisciente de toda a cena, que, em sua imensa variedade, é retratada do alto. Trata-se de um procedimento típico deste artista, decorrente, segundo alguns estudiosos, de sua formação como cartógrafo.

Mas é justamente este aspecto que torna curioso o segundo quadro, cuja perspectiva contraria a atitude tradicional do pintor. Pierre Jensen, na sua História geral da arte, chama a atenção para o fato de Bruegel ter invertido o seu ponto de vista habitual, situando o seu olhar próximo ao chão, onde estão os cegos da pintura que olham para cima. Tal fato também parece não ter escapado à percepção de Baudelaire, e de tal maneira que ele o transforma na própria temática de seu poema.

Assim, e ao contrário do pintor, literalmente interessado no conteúdo narrativo de seu tema, Baudelaire, na sua leitura do quadro, não parece tão interessado na parábola por ele ilustrada, mas neste que é um aspecto essencialmente plástico de sua configuração: o gesto desconcertante das figuras cujos olhos, "d'ou la divine étincelle est partie,/...restent levés/ Au ciel”. Indiferente à interpretação alegórica convencional do quadro, portanto, Baudelaire parece ver nesta pintura sobretudo o detalhe postural das figuras retratadas. 
À semelhança do pintor, o poeta se coloca na mesma posição dos cegos, e exclama ao leitor: "Vois! je me traîne aussi! Mais, plus qu'eux hébété ...", sugerindo que talvez não estivesse tão alheio ao sentido da alegoria à sua frente. Talvez, apenas, atentando para a flagrante ausência de uma qualquer testemunha ocular no quadro, o reformulasse, transformando o que seria uma provável condenação da cegueira atribuída aos fariseus num lamento pela comum escuridão e ignorância que une os seres humanos, inclusive o pintor e o poeta, cujos olhares implícitos em suas respectivas obras denotam posições similares, solidárias à atitude algo patética e perdida de seus personagens, que miram o alto de onde viria a luz que não podem captar.

Se é verdade, como comenta Derrida, "qu'on reconnaît les aveugles à leur manière de tourner la tête en haut", será talvez porque, como indaga, "l'oeil intérieur cherche à percevoir l'éternelle lumière qui luit dans l'autre monde?" Talvez Baudelaire não tenha escolhido ao acaso esta pintura para questionar uma realidade que se lhe afigura cada vez mais despojada de valor e de sentido, iluminando com o seu poema detalhes composicionais de um quadro cuja interpretação deveria ser outra.

Além disso, Bruegel não era exatamente um pintor que se poderia chamar de ortodoxo. Assim como não há testemunhas oculares na sua representação da parábola dos cegos, também é patente a indiferença dos espectadores, em muitos de seus quadros, para com o drama da altura e da profundidade, critérios tradicionalmente utilizados na avaliação das obras humanas e na valoração dos sujeitos. E. H. Gombrich comenta sobre como o impulso iconoclasta que já se pressente em Bruegel teria evoluído ao longo do tempo:

\footnotetext{
${ }^{1}$ DERRIDA, 1992. p. 51. Algo semelhante é sugerido por Platão no mito da caverna, que estabelece a diferença entre o homem iludido, preso à crença na realidade das aparências, meras sombras, e o filósofo esclarecido, que ousa libertar-se dos grilhões do engano e buscar o conhecimento onde brilha a verdadeira luz, para, em seguida, comunicá-lo aos prisioneiros da escuridão. Platão, "O mito da caverna", in: A república.
} 
The symbol has been recognized as a force of social control and cohesion. [...] As we move from the hierarchical society of the past, problems of symbols and values became, in fact, more acute. We have seen how strongly this type of society imprinted its frame of reference on the terms in which art was conceived. The "noble" and the "vulgar", the "high" and the "low", the "dignified" and the "common" are today not much more than pale, fading metaphors for what were once tangible realities. We need not mourn their passing away in order to realize that there an area of metaphor is passing out of our consciousness which, for centuries if not longer, gave man a symbol of value, however crude. It did even more - it provided a bait or reward of the "process of civilization" itself. ${ }^{2}$

Não se pode afirmar com exatidão se outros quadros de Bruegel, como A adoração dos magos numa paisagem de inverno e o Transporte da cruz, por exemplo, poderiam já conter um tal impulso revisionista. De qualquer maneira, é curioso observar como, no primeiro, Bruegel empurra a cena da adoração para a borda esquerda do quadro, ressaltando não o motivo religioso, mas um fenômeno natural, a neve e a vida numa aldeia no inverno. Embora ocupe o centro da cena no segundo quadro, a figura de Cristo é praticamente engolida pela multidão que vem da cidade, ao fundo à esquerda, e que num movimento largo caminha a pé ou a cavalo em direção ao Gólgota. A maior parte das pessoas que participam desta excursão popular não parece compreender o significado da crucificação iminente.

A mesma indiferença para com o que constituiria o motivo central do quadro - que escaparia à percepção do leitor se não fosse o indicativo do título - ocorre de maneira flagrante na única pintura que realizou sobre um tema da mitologia grega, A queda de Ícaro. Não obstante o seu destino trágico, a figura de Ícaro é comumente celebrada pela coragem e temeridade de seu gesto, o gesto irreverente dos jovens, capazes de pôr em risco a própria vida em nome da aventura da descoberta, fugindo assim da mediania em que

${ }^{2}$ GOMBRICH, 1994. p. 27. 
se conserva em segurança Dédalo, seu pai; celebrado, por sua vez, pela prudência.

Alheio a esta interpretação, porém, Bruegel o retrata de maneira grotesca, reduzindo sua figura a duas pernas e a uma mão que se agitam fora da água, num canto quase imperceptível do lado direito do quadro, evocando ainda os três personagens mencionados na mais conhecida versão do mito grego na época, a adaptada por Ovídio em As metamorfoses: o lavrador, o pastor e o pescador, que contemplariam Ícaro e Dédalo voando no céu, espantando-se e julgando ver deuses que se aproximavam do éter. No quadro, porém, só o guardador de rebanhos contempla o céu, mas sem espanto, e todos continuam calmamente as suas ocupações, sem se preocuparem com o afogado.

Em seu livro Museum of words, James Heffernan comenta como o sentido moral atribuído à pintura é em larga escala construído pelas palavras do título com as quais o museu o rotulou:

Consider for a moment what we could make of this painting without its title. Even if its three figures should remind us of book 8 of The metamorphoses, where the flight of Daedalus and his son is said to have been witnessed with stupefaction by "some fishermen, or a shepherd, leaning upon his crook, or a ploughman, on his plowhandles", could we recognize the splashing legs as those of Icarus? [...]. Would we even know that the splashing legs belong to a drowning man and not to a swimmer happily disporting while the ploughman toils? [...] The honest answer to all of these questions is no. [...] the curator's label leads us to see in the painting a meaning borrowed from another Bruegel painting which hangs in Brussel's Van Buuren Museum and which is almost identical to the Beaux Arts "Icarus" except - a crucial except - for the presence of a winged man flying through the sky at the very top. In the Beaux Arts picture, this unmistakable sign of Daedalus - the sign that would lead us to identify the splashing legs as those of the fallen son - is missing. Its place is taken by the key word in the title. ${ }^{3}$

\footnotetext{
${ }^{3}$ HEFFERNAN, 1993. p. 148.
} 
Portanto, o que o quadro de Bruegel evidencia é a dependência do observador de um conhecimento prévio de um texto mesmo o curto "texto" de um título - para a "correta" interpretação da pintura, mostrando a clássica hegemonia de um sobre a outra. Afinal, por que teria Bruegel removido a figura de Dédalo de um dos quadros? Seria um gesto de insubordinação contra a escrita, transformando a paisagem menos numa ilustração presa a um sentido pré-estabelecido do que numa imagem autônoma, aberta a vários significados?

Como se percebe em todos esses quadros, embora não possa fugir à determinação da palavra geradora, dominante em sua época, Bruegel procura de todos os modos contorná-la e disfarçá-la na pintura, de modo que a imagem impressione mais espontânea e diretamente do que o texto nela implícito. Segundo uma perspectiva moderna, seria possível dizer que Bruegel parece apelar em sua obra para a "cegueira" do observador, entendendo-a como o despojamento de informações e de doutrinas, levando-o a ver seus quadros com um "olhar inocente".

O conceito do "olhar inocente" é definido por E. H. Gombrich como o mito, persistente e multiforme, da visão pura, neutra, de um olhar transparente e não mediatizado, capaz de apreender o realem-si, como forma total de exterioridade. ${ }^{4}$ Ora, é este mesmo olhar que Baudelaire mais tarde definiria em Opintor da vida moderna como o olhar inaugural que o artista deveria partilhar com a criança, o poeta e o convalescente no mundo em vertiginosa transformação da modernidade. Para Gombrich e Nelson Goodman, este seria um "olhar cego".

Tal definição cria um paradoxo quando se considera o quê um verdadeiro cego pode apreender de uma pintura: nada além de conceitos e definições alheias à experiência direta da visão - "this sort of pure visual perception, freed from concerns with function, use, and labels" - experiência que, para W.J.T. Mitchell, "is not the

${ }^{4}$ GOMBRICH, 1968. 
'natural' thing that the eye does (whatever it would be), but perhaps the most highly sophisticated sort of seeing that we do":

The innocent eye is a metaphor for a highly experienced and cultivated sort of vision. When this metaphor becomes literalized, when we try to postulate a foundational experience of "pure" vision, a merely mechanical process uncontaminated by imagination, purpose, or desire, we invariably rediscover one of the few maxims on which Gombrich and Nelson Goodman agree: the innocent eye is blind. The capacity for a purely physical vision is supposed to be forever inaccessible to the blind turns out to be itself a kind of blindness. ${ }^{5}$

E o que dizer de cegos que contemplam o céu? A esse respeito, Rosalind Krauss comenta sobre a função referencial de imagens totalizadoras como as do mar e do céu:

The sea and sky are a way of packaging 'the world' as a totalized image, as a picture of completeness, as a field constituted by the logic of its own frame. But its frame is a frame of exclusions and its field is the work of ideological construction. ${ }^{6}$

Ao lado do entusiasmo modernista pelo "olhar inocente", porém, há uma sensação de irremediável perda. Quando Bruegel pinta provérbios, ainda que de um ponto de vista crítico, ele não está propriamente submetendo a pintura ao discurso verbal, mas expressando as condições de um mundo onde a arte de contar era possível porque a experiência vivida era partilhada pelos indivíduos de uma mesma comunidade. A relação destes indivíduos para com o passado e a memória era, portanto, de respeito e reverência, uma vez que havia um saber e uma verdade transmitidos pela palavra e reforçados pela imagem ao longo das gerações. Assim, Bruegel criticava não a verdade dos provérbios (da palavra), mas a surdez (ou cegueira) dos homens que não a escutavam (ou não a percebiam).

\footnotetext{
${ }^{5}$ MITCHELL, 1987. p. 118.

${ }^{6}$ KRAUSS, 1992.
} 
Por isso, o que hoje é compreendido como uma moldura de exclusões, delimitando o campo de uma construção ideológica, surgiu, de fato, como uma necessidade de transmissão de um saber prático que os jovens poderiam receber com proveito e cuja validade poderia ser confirmada na experiência em comunidade. A natureza do saber era tão pragmática que não raro este tomava a forma de uma advertência, de um conselho, algo que hoje já não é possível ou sequer compreensível, dado o isolamento crescente dos indivíduos em seu mundo particular e privado. ${ }^{7}$

A era das conquistas tecnológicas inaugura, de maneira violenta, toda uma mudança na capacidade da percepção visual. Vêse, pela primeira vez, o microcosmos e o macrocosmos, vê-se à distância, acima, do outro lado do mundo; vê-se, com a fotografia e o cinema, até mesmo através das malhas do tempo. A humanidade vê como nunca, e como nunca parece ter estado tão cega.

O que a leitura comparada deste infinito circuito de textos e imagens revela é que ou se procura no "céu" da pintura o que não está lá, que é o texto da escritura, ou se procura o que lá está, a pintura de um "céu", amálgama de tintas azuis e ilusão de abóbada sobre uma tela plana, percepção que transforma automaticamente o observador num personagem tão perdido quanto os cegos representados no quadro, deslizando sobre uma superfície lisa e escorregadia onde qualquer ponto de apoio é inútil.

"Ceci n'est pas une pipe" - explicaria Magritte posteriormente, pacientemente, sob a imagem perfeitamente reconhecível de um cachimbo - numa lição de pintura moderna que é uma defesa da natureza silenciosa e autêntica da pintura. A pintura moderna diz apenas que não é "poesia muda". A pintura moderna é também o grande desafio lançado aos poetas, fazendo-os pensar no quanto têm de pintores "cegos", ou no que estão porventura deixando de ver enquanto dormem embalados pelo ruído e deslumbrados pelo poder de suas palavras.

7 GAGNEBIN, 1987. 
Para Derrida, "un dessin d'aveugle est un dessin d'aveugle", o que parece valer tanto para a pintura quanto para a literatura, particularmente no caso do quadro e do texto aqui confrontados, que têm na cegueira a sua temática. Assim, compreendendo os cegos do poema de Baudelaire como uma alegoria dos pintores modernos, podemos vê-los "tateando" com os olhos um novo "céu" - a recém-descoberta e paradoxal escuridão da pintura pura, a enorme superfície que se abre e se oferece à aventura até então inédita da exploração de formas, de linhas, de luzes e sobretudo das cores, subitamente libertas de significado.

Assim, sob a alcunha de qualquer "ismo" vanguardista, um novo céu - substituído no poema por uma expressão de indeterminação: "on ne sait où" - descortina-se para a arte, anunciando o século da imagem: cética, cínica, lúdica, lúbrica, lírica, onírica, histérica, histriônica, cor: "Contemple-les, mon âme, ils sont vraiment affreux!/Pareils aux manequins, vaguement ridicules;/Terribles, singuliers comme les sonambules;/Dardant on ne sait où leurs globes ténébreux".

O mesmo não acontece se compreendemos os cegos do poema como uma alegoria dos poetas ou de qualquer artífice da palavra. Doentes, privados do antigo poder dos olhos privilegiados com que viam, previam, descreviam, definiam e legislavam sobre o invisível, os escritores modernos transformam-se no alvo cruel da ironia de Baudelaire, que interroga o que eles ainda estariam a procurar no "céu".

Observe-se que, ao contrário da analogia anterior, melhor tecida na primeira estrofe, o "céu" da segunda estrofe é totalmente distinto: não é uma tela nem sequer uma página em branco, é tão somente uma palavra: "ciel", que parece esvaziar-se juntamente com a substância divina e o brilho intrínseco do olhar, com a interdição da distância ("au loin") e da profundidade, expressa num outro gesto postural, atitude de reflexão, posição de recolhimento, encolhimento e contemplação interior comum aos pensadores, já então definitivamente abandonada pelos cegos ("on ne les voit jamais vers les pavés/Pencher rêveusement leur tête appesantie"). 
Neste poema, a palavra "céu" - apesar do peso e da profundidade resultantes de séculos de história e de memória - subitamente vê-se privada da magia ou da fé que a fazia ascender apesar da bagagem, e pensar no azul, no infinito, na luz e em tudo o que ela não é, mas evoca. Ou evocava, nos velhos tempos dominados e sufocados pelas narrativas e pelo verbo. Não por acaso a "noite ilimitada" é irmã do "eterno silêncio" que se abate sobre o palco da modernidade - a cidade. Despojados da palavra, resta aos cegos o engano, ora de se julgarem felizes, talvez; ora de confundirem o espectador com a aparência de uma jubilosa celebração, tanto mais bizarra, tanto mais atroz, quanto mais artificial a denuncia o poeta, neste que é um herético, porém profético, soneto.

Cauteloso, no entanto, Baudelaire destaca no quadro não a derrocada dos cegos, mas a aventura reiterada da empreitada humana em busca do saber, onde as mãos se antecipam aos olhos, avançando, tateando no escuro, pressentindo a queda e ainda assim prosseguindo, os olhos inutilmente voltados para cima. Como os cegos, o poeta e o pintor descobrem, na modernidade, que tateiam no escuro. Que nada realmente sabem. Que são, talvez, guias duvidosos, que perderam sua legitimidade em face de uma matéria duvidosa.

No ato da representação, o pintor e o poeta unem-se pelo traço que, em ambos os casos, é invisível em si mesmo:

L'heterogénéité reste abyssale entre la chose dessinée et le trait dessinant, fût-ce entre une chose représentée et sa répresentation, le modèle et l'image. La nuit de cet abîme peut s'interpréter de deux façons, soit comme la veille ou la mémoire du jour, autrement dit une réserve de visibilité (la perspective anticipatrice ou la rétrospective anamnésique), soit comme radicalement et définitivement étrangère à la phénoménalité du jour. ${ }^{8}$

Derrida tece suas observações a partir de um comentário de Baudelaire sobre o desenhista Constantin Guys, no capítulo "A arte mnemônica" em O pintor da vida moderna. Diz o poeta:

${ }^{8}$ DERRIDA, 1992. p. 50. 
Refiro-me ao método de desenhar de G. Ele desenha de memória, e não a partir do modelo.[...] Na verdade, todos os bons e verdadeiros desenhistas desenham a partir da imagem inscrita no próprio cérebro, e não a partir da natureza. [...] Quando um verdadeiro artista chega à execução definitiva de sua obra, o modelo lhe será mais um embaraço do que um auxílio.?

No olhar "sintético e abreviador" de Constantin Guys, associado ao modo como fundamenta a sua criação na memória, Baudelaire parece encontrar a própria expressão de seu conceito de modernidade - "A Modernidade é o transitório, o efêmero, o contingente, é a metade da arte, sendo a outra metade o eterno e o imutável". Mas a própria natureza dos avanços tecnológicos mostra que ser moderno é menos desejar descobrir o que persiste naquilo que passa, do que tentar retê-lo, impedindo-o de passar. Ser moderno, por isso, tem algo de desesperadamente criminoso. Derrida associa a grande filiação dos escritores cegos, de Homero a Joyce, de Milton a Borges, à dos autores de obras "assassinas", como The picture of Dorian Graye The oval portrait: Oscar Wilde e Edgar Allan Poe, ambos precursores da modernidade, ambos preocupados com o espelho, o reflexo, o duplo, a representação e o seu inevitável parentesco com a morte - perda, interrupção, destruição, ruína: invisibilidade.

Invisibilidade que, como comenta Derrida, advém não só da natureza do traço, mas do fato de que escrever e desenhar são atividades que acontecem "no escuro": seja da memória do já visto, seja da imaginação do ainda não visto, que se deseja projetar. A invisibilidade do traço faz da obra de arte uma provocação ao leitor e ao observador, na medida em que deles exige uma atitude correspondente: vaguear, como o cego, no escuro da imaginação, à procura de um sentido.

${ }^{9}$ BAUDELAIRE, 1988. p. 178. 


\section{O "país dos cegos" de H. G. Wells e o de José Saramago}

"- Has no one told you, 'In the Country of the Blind the One-Eyed man is King"?

- What is blind?, asked the blind man carelessly over his shoulder..."

H.G. Wells, "The Country of the Blind"

Um escritor português contemporâneo tem dedicado grande atenção em suas obras às correlações entre a pintura e a literatura, tem refletido seriamente a respeito do paradoxo visão \& cegueira, insistindo na "responsabilidade de ter olhos quando os outros os perderam": José Saramago, que também parece dever algo de sua atração pelas artes plásticas ao pensamento de Charles Baudelaire e à pintura de Pieter Bruegel - cujas obras, aliás, são freqüentemente citadas em seus livros. ${ }^{10}$

Não por acaso, é ele o autor de dois romances - Manual de pintura e caligrafia e Ensaio sobre a cegueira - que abordam diretamente alguns dos temas considerados neste ensaio, e que já se anunciavam à época das vanguardas. No primeiro, trata da construção da auto-imagem do artista, e no segundo, do papel social

\footnotetext{
${ }^{10}$ Em Manual de pintura e caligrafia, Saramago cita: "Como naquele desenho célebre de Bruegel (Pieter), aparece por trás de mim um perfil talhado a enxó, e ouço a voz dizer-me, uma vez mais, que não nasci ainda". Em Ensaio sobre a cegueira, encontra-se a referência ao quadro "A parábola dos cegos": "O pior é que as famílias, sobretudo as menos numerosas, rapidamente se tornaram em famílias completas de cegos, deixando portanto de haver quem os pudesse guiar e guardar, e deles proteger a comunidade de vizinhos com boa vista, e estava claro que não podiam esses cegos, por muito pai, mãe e filho que fossem, cuidar uns dos outros, ou teria de suceder-lhes o mesmo que aos cegos da pintura, caminhando juntos, caindo juntos e juntos morrendo." Além destes dois trabalhos, pode-se mencionar nesta linha $O$ Evangelho segundo Jesus Cristo, que parte de uma descrição ecfrástica de uma gravura de Albrecht Dürer, e O ano da morte de Ricardo Reis, onde o autor joga com a dinâmica do visível e do invisível para romancear a história e discutir conceitos como os limites entre o real e a ficção.
} 
da arte, discutindo estes assuntos às vésperas do fim do milênio e mostrando as contradições que persistiram ao longo do século. Assim, no mundo de que fala Saramago, conquistas da razão e da ciência até pouco tempo inimagináveis convivem com situações do mais puro obscurantismo social, a tecnologia avança lado a lado com misticismos e fanatismos de toda sorte, que aparecem para compensar a ganância e a abstinência moral características da época, contra as quais se insurge o autor.

Lamentando a perda do poder utópico dos vanguardistas militantes, Saramago revela-se insatisfeito com a fachada artificial e enganosa do pós-modernismo, que não se tornou o palco para o exercício da liberdade humana - como queria Baudelaire ao rejeitar nas escolas artísticas a limitação do doutrinamento - mas que, ao contrário, parece ocultar, sob um excesso de claridade e sob um jogo de sedução visual, uma crescente incapacidade de ver, de analisar e de raciocinar.

Anterior ao Ensaio (1995), o Manual (1977) aborda a questão do sujeito, a afirmação do artista no mundo e a sua busca de identidade. Trata-se, na verdade, de um texto autobiográfico disfarçado numa proposta de diário de viagens. Pondo em questão todos os gêneros artísticos introspectivos e auto-referenciais que tanto sucesso alcançaram nos últimos tempos, o Manual - que não se abstém de um título bem prescritivo - procura relatar os percalços da arte através dos tempos e os conflitos do artista para quem - à semelhança de Constantin Guys, estudado por Baudelaire - a obra ainda é mais importante do que o nome.

A questão da identidade é fundamental neste texto. O artista (H.) divaga vertiginosamente em torno do nome de seu modelo, cuja inicial (S.) dá margens a infinitas especulações, incluindo a possibilidade de que o modelo seja o próprio criador. "Sempre soube que o retrato justo nunca foi o retrato feito" - anuncia ele, logo no início de sua trajetória, problematizando a natureza especular da busca que deverá levá-lo não ao encontro da realidade exterior que supõe ser o alvo principal de sua busca, mas da realidade íntima e ainda desconhecida de seus pensamentos, sonhos e ideais. Daí a confissão: 
"Quem retrata, a si mesmo se retrata. [...] Não gostando de me ver retratado nos retratos que doutros pinto, gostarei de me ver escrito nesta outra alternativa de retrato que é o manuscrito, e em que acabei mais por retratar-me do que retratar?" 11

O romance trabalha com duas dimensões da auto-representação - uma plástica, a outra literária - confundindo-as na mesma dimensão auto-referencial, o que possibilita uma discussão correlata entre os gêneros do retrato na pintura e do diário na literatura. O protagonista é um pintor que deseja experimentar-se na escrita, assim como o autor é um escritor que deseja experimentar-se na pintura - ainda que em termos de reflexões de natureza plástica.

Esta estratégia permite que o Manual se apresente como uma antítese à concepção mesma dos "manuais", uma vez que as lições literárias nascem da percepção eminentemente plástica - e, portanto, leiga - do protagonista, assim como as lições plásticas têm o sabor do ineditismo visual do verdadeiro escritor que lhes dá voz no romance, num sugestivo cruzamento em que a busca da identidade pessoal confunde-se com a necessidade de libertação de dogmas e de teorias para a compreensão, através da experiência, da identidade de cada linguagem expressiva: pintura, caligrafia. Através de uma viagem pela história da arte e da representação relatada através da escrita, H. consegue, finalmente, libertar-se da profissão de pintor - e S., talvez, da condição de escritor profissional - e fazer da pintura, o que também vale para a escritura, o instrumento de um verdadeiro encontro com o espelho, através da definição de um estilo próprio, liberto de necessidades outras como a servidão a um gênero ou a um público específicos e, sobretudo, da mercantilização da própria atividade artística como forma de sobrevivência. Recusando-se a fazer concessões, o artista reencontra-se finalmente como um criador, ainda que incompreendido e solitário como o foram os vanguardistas do início do século XX.

O entusiasmo dos primeiros tempos, revelado no Manual, acaba por ceder ao pessimismo presente no romance Ensaio sobre

${ }^{11}$ SARAMAGO, 1992. p. 79. 
a cegueira, provavelmente inspirado no quadro de Bruegel já discutido, mas que também evoca um conto de H. G. Wells intitulado The country of the blind, substituindo-se, neste, o otimismo poético por um sentimento derrotista. Talvez motivado pela contradição de um tempo no qual luzes de néon roubam definitivamente a aura às produções humanas, Saramago fala com amargura de um final de século onde a visão deixa de ser metáfora da razão e onde os visionários, como o protagonista da utopia de Wells, não têm nenhum lugar.

Construído a partir de um observador privilegiado, e girando em torno de um provérbio popular - "Em terra de cego quem tem um olho é rei" - o texto em questão propõe-se a investigar a natureza da cegueira numa época em que a visão não é sinônimo de saber, mas de poder.

No romance de Saramago, a protagonista é uma mulher. Porém não a veremos olhar o céu com muita freqüência. Única personagem a conservar a visão quando o mal da cegueira "branca" se alastra na comunidade - vitimando logo de início, por ironia, seu marido, um oftalmologista -, é através dela que a história é narrada.

Contraponto dos cegos, guia de cegos, naturalmente rainha em terra de cegos, a posição de observação que assume a mulher do médico é sempre distanciada e privilegiada, vantagem da qual ela revela consciência e medo, e que procura ocultar estabelecendo deste o início um princípio de exclusão, de diferenciação, de separação. De um lado, o marido, os amigos, os eleitos, aos quais cabe a sinceridade, a lealdade, a dedicação, quando não mesmo o sacrifício. Do outro, a massa de cegos anônimos, bárbaros, bestiais, perdidos na irracionalidade e potencialmente perigosos, dos quais é preciso guardar segredos e distância.

Acompanhando os passos desta personagem, percebe-se que ela olha insistentemente para o chão, como convém a um guia cônscio de sua responsabilidade. A utilidade de seus olhos é perfeitamente demarcada pela capacidade de memorizar trajetos, organizar filas, abrir e fechar convencionalmente as portas, identificar o melhor flanco de ataque para defender-se dos inimigos e, princi- 
palmente, providenciar alimento para o grupo. Além disso, sobramlhe alguns momentos à noite para ler para os cegos, à luz de uma candeia, sobre "a história de uma humanidade que antes de nós existiu".

A fábula de Saramago não oferece muitas opções de resposta à pergunta lançada por Baudelaire, uma vez que o romancista não parece ter atentado para aquele detalhe postural dos cegos que tanto intrigou o poeta. Quando olham para o céu, os cegos de Saramago sabem exatamente o que procuram - água para matar a sede, e se ficam perturbados é de poder obtê-la de um céu que lhes parece tão uniforme, tão sem mistério, tão vazio e claro como tudo o mais: “...e os cegos, os cegos, de boca aberta, abrindo também os olhos para o céu branco, parece impossível como pode chover de um céu assim". ${ }^{12}$

Ao olhar para o chão, a mulher do médico, contudo, não se perde em pensamentos nem em divagações, mas em decisões práticas e objetivas, que não ocultam um inconfessável medo da responsabilidade de ser - ou, talvez, a secreta dúvida de não ser, que o romance também não confessa - a única vidente do grupo. Este é o elemento contraditório desta personagem. Explicitamente criada para enfatizar a visão, instrumento da razão, como a última trincheira de esperança salvacionista num mundo de cegos, loucos e doentes, a "mulher do médico" acaba revelando as contradições desta crença.

Aparentemente escravizada aos cegos, aos quais se dedica com generosidade e nobreza, os olhos desta mulher não conseguem esconder que ela também os escraviza, na medida em que os impede de se arriscar mais profundamente na nova situação em que se encontram. Ancorando-os, portanto, à situação anterior, ela tenta conservá-los presos a si, presos a uma visão de mundo ultrapassada e descontextualizada, presos, enfim, a um "mundo de visão" no interior do qual é ela mesma - com a sua remanescente capacidade de ver - que se encontra ilhada, perdida e sozinha.

${ }^{12}$ SARAMAGO, 1995. p. 226. 
"Graças aos teus olhos é que estamos vivos", diz "a mulher dos óculos escuros", ao que ela replica: "Também o estaríamos se eu fosse cega, o mundo está cheio de cegos vivos."13 A contradição sobre a utilidade da visão, aparentemente tão evidente ao longo da história, insinua-se em observações desse tipo, sugerindo que o temor desta mulher é menos o de perder a visão em si do que um referencial racional comum - uma idéia de mundo - até então partilhado com o seu grupo.

Talvez por isso, tudo o que o olhar desta mulher - "d'où la divine étincelle est partie", e não por causas orgânicas - nos faculta ver são as desgraças decorrentes da cegueira que se abateu sobre a civilização. Cenas de barbárie, animalescas, sombrias, apocalípticas, descortinam-se aos olhos do leitor. Presa entre quatro paredes ou ao traçado dos caminhos predeterminados de um mundo em relação ao qual os outros se mostram cada vez mais indiferentes, quando olha para cima a mulher do médico nada procura, nada parece ver além do "céu que está tapado", e não há a menor sombra de dúvida em sua afirmação. A dúvida, se existe alguma, só lhe ocorre no último parágrafo do romance, no momento em que, estando todos os demais a recuperar milagrosamente a visão, levanta-se e vai até a janela: "Olhou para baixo, para a rua coberta de lixo, para as pessoas que gritavam e cantavam. Depois levantou a cabeça para o céu e viu-o todo branco, Chegou a minha vez, pensou. O medo súbito fê-la baixar os olhos. A cidade ainda ali estava." ${ }^{14}$

O movimento hesitante do olhar desta mulher revela muito a respeito da natureza de sua visão. O seu olhar, sinônimo da razão, não consegue ser metáfora de mais nada. Privado da vontade imaginativa, a percepção essencialmente racional desta mulher acaba por revelar tudo o que a razão disfarça através de seus inteligentes mecanismos ilusionistas: todo o jogo de interesses, de poder, de autodefesa, de domínio e de medo que faz de toda visão de mundo,

\footnotetext{
13 SARAMAGO, 1995. p. 282.

${ }^{14}$ SARAMAGO, 1995. p. 310.
} 
sobretudo a que se tem como natural, própria do olhar inocente, uma visão construída, uma visão ideológica. Talvez por isso, forçada a encarar este fato, a protagonista de Saramago desvie rapidamente os olhos do céu denunciador para o sítio mais confortável do rés-do-chão onde se desenrola a sua fábula soturna, amarga e desesperançada.

No conto de H. G. Wells, publicado em 1906, o argumento é basicamente o mesmo, com algumas variações interessantes. Uma epidemia de cegueira ataca um grupo de pessoas numa determinada área isolada por um terremoto. Com o decorrer do tempo, porém, a comunidade cega acaba por organizar um novo modo de "estarno-mundo", um modo não-visual, desenvolvendo agudamente outros sentidos que lhes permitem perfeitamente organizar a sociedade em que vivem de maneira equilibrada, justa e agradável.

Wells não utiliza o par visão=razão usado por Saramago, e, portanto, a cegueira não é um impedimento em seu conto à organização de um grupamento humano ordenado e funcionante. A audição, o tato e os demais sentidos servem perfeitamente para a reorganização de um esquema de sobrevivência satisfatório, onde até mesmo a linguagem se reestrutura, adequando-se à expressão de um mundo sem olhos:

Blind men of genius had arisen among them and questioned the shreds of belief and tradition they had brought with them from their seeing days, and had dismissed these things as the fancies and replaced them with new and saner explanations. Much of their imagination had shrivelled with their eyes, and they had made for themselves new imaginations with their ever more sensitive ears and finger-tips. ${ }^{15}$

O que chama a atenção na história de Wells, porém, é o poder evocativo que a visão adquire no contexto. Como na história de Saramago, há no conto de Wells um candidato a "rei" em terra de cego: um homem que vê, um visitante casual, que ao chegar ao país dos cegos aspira automaticamente a dominá-los e a convencê-los da

15 WELLS, 1979. p. 132. 
supremacia da visão sobre os demais sentidos. À diferença da "mulher do médico" do romance de Saramago, o protagonista de Wells, contudo, não faz segredo para si nem para os outros, e muito menos para o leitor, deste objetivo - ou destinação - que lhe parece natural e merecido.

Desde o início percebe-se a franqueza do protagonista Nunez: ele quer dominar, sabe da sua ambição e se crê merecedor de um reinado, já que possui uma vantagem sobre os demais. Outra diferença marcante reside na sua atitude: está sempre olhando para o céu, mostrando a todos, indiscriminadamente, que vê e o que vê, e o que vê é invariavelmente belo e inspirador, mesmo para os cegos que não acreditam e não podem compreender o seu discurso:

He tried at first on several occasions to tell them of sight. Once or twice one or two of them attended to him, they sat with faces downcast and ears turned intelligentelly towards him, and he did his best to tell them what it was to see. [...] He spoke of the beauties of sight, of watching the mountains, of the sky and the sunrise, and they heard him with amuse incredulity that presently became condemnatory. They told him that there were indeed no mountains at all, but that the end of the rocks where the llamas grazed was indeed the end of the world. [...] So far as he could describe sky and clouds and stars to them it seemed to them a hideous void, a terrible blankness in the place of the smooth roof to things in which they believed. ${ }^{16}$

Numa resposta à questão proposta por Baudelaire, os cegos de Wells mostram como as pessoas buscam no "céu" uma explicação e uma esperança condizentes com as suas expectativas e possibilidades. Assim, os homens daquele povoado buscam no céu apenas aquilo que esperam encontrar, e encontram exatamente o que procuram: a segurança de um teto firme como a rocha mas estranhamente macio ao tato, capaz de protegê-los num mundo fechado onde tudo funciona perfeitamente e nada os pode ameaçar.

${ }^{16}$ WELLS, 1979. p. 136. 
Através de Nunez, porém, Wells mostra que a capacidade de ver vai muito além da mera capacidade de raciocinar. Acompanhamos o percurso e o aprendizado deste homem em terra de cegos, desde o momento de sua revolta inicial ("I see I must bring them to reason!"), até o momento final, em que passa a compreender que o desejo de reinados não se coaduna com o desejo de ver, sendo esta a natureza da sua cegueira.

Afinal, os cegos estão organizados e convictos em seu próprio mundo. Suprem as suas necessidades e superam no aspecto prático qualquer vantagem que o homem supunha que seus olhos pudessem ter. O homem que vê é que é obrigado a sucumbir à sociedade dos cegos para poder sobreviver e vai paulatinamente perdendo a arrogância e questionando-se a respeito da necessidade real da visão. Apaixona-se por uma cega e passa a considerar a possibilidade de uma cirurgia radical de remoção dos globos oculares - já que a visão é a sua catarata naquele universo - a fim de poder integrar-se de vez, como um lúcido e não como um louco, no País dos cegos.

Mas é neste momento que o poder metafórico da visão se revela inteiro no conto de Wells como uma contradição: como o reabilitador do invisível, do sonho, da fantasia, da posse daquilo que todos consideram impossível, absurdo, insano, mas que é absolutamente verdadeiro para o homem que vê. Contemplando cada vez mais o céu e vendo, solitariamente, o que escapa aos cegos, Nunez sente-se grato:

Nunez had an eye for all beautiful things, and it seemed to him that the glow upon the snowfields and glaciers that rose about the valley was the most beautiful thing he had ever seen. His eyes went from that inaccessible glory to the village and irrigated fields, fast sinking into the twilight, and suddenly a wave of emotion took him, and he thanked God from the bottom of his heart that the power of sight had been given to him. ${ }^{17}$

${ }^{17}$ WELLS, 1979. p. 134. 
É, portanto, o temor de perder a sua verdade, a sua capacidade de percepção tornada singular naquele contexto, "la divine étincelle de ses yeux", que impulsiona Nunez a assumir o risco e o terror do enfrentamento da própria solidão, obrigando-o a fugir daquele lugar organizado e bem-funcionante à procura da sensação de beleza, leveza e esperança que a graça de ver lhe restitui num contexto em que a razão pura é que é associada à cegueira, ao limite, à moldura: como nos quadros, à ditadura dos quatro cantos determinados da tela.

Cotejar a visão do "céu tapado" para a vidente de Saramago com "the illimitable vastness of the sky" para o vidente de Wells é, no mínimo, intrigante. Estão ambos, ao final do romance e do conto, em posições semelhantes, contemplando à distância os seus respectivos mundos: uma desejando desesperadamente voltar, o outro desejando desesperadamente escapar, e pelo mesmo motivo: o medo de perder o que consideram o bem mais precioso - a capacidade de ver.

Assim, enquanto a mulher do médico desvia os olhos do céu à procura dos outros e do conforto paradoxal que a cidade apocalíptica e medonha aos seus pés lhe oferece - em cuja existência encontra, afinal, o abrigo de "um teto de rocha, estranhamente macio" sob o qual poderá sempre obter uma confirmação exterior da validade de sua capacidade de ver (da qual, talvez, duvide) -, Nunez desvia os olhos da cidade nem apocalíptica nem medonha, mas ultra-organizada dos cegos, e de seu céu implacavelmente sedutor, à procura do desconhecido, do risco, de algo mais condizente com as suas aspirações:

There were deep misterious shadows in the gorge, blue deepening into purple, and purple into a luminous darkness, and overhead was the illimitable vastness of the sky. But he heeded these things no longer, but lay quite inactive there, smiling as if he were satisfied merely to have escaped from the valley of the Blind in which he had thought to be King. ${ }^{18}$

${ }^{18}$ WELLS, 1979. p. 146. 
Afinal, que procuram no céu todos esses cegos?.. Para Saramago, procuram o fim do mundo, que já encontraram ou estão em vias de encontrar, graças à perda da visão racional, candeia que deveria lançar sombras e formas na excessiva claridade exposta aos olhos destemperados dos seus contemporâneos, fazendo-os pensar. Para Wells, procuram uma adequação coletiva, feliz e simplória, ou uma inspiração solitária, pessoal e temerária, aos limites de suas percepções e de seus desejos de intervenção na realidade.

O que parece assustador nesses textos é que ambos falam, cada um ao seu modo e por razões diversas, de um mundo onde nenhum visionário, entendendo-se com isso um poeta ou pessoa dotada de imaginação, conseguiria existir, como se a própria idéia de mundo - caótico como o de Saramago ou utópico como o de Wells - fosse avessa à "divine étincelle" que brilha no olhar irrequieto dessas criaturas. O mesmo não parece ocorrer com os "cegos", aqueles que, para Baudelaire, "pareils aux mannequins, vaguement ridicules/ terribles, singuliers comme les sonnambules", que cantam e riem, contentes ou descontentes na prisão da crença em suas realidades.

Por isso, abandonados para sempre pelo seu visitante visionário, os cegos de Wells continuarão vivendo num paraíso artificialmente construído, sem experimentar jamais as torturas - e sem sequer desconfiar das alegrias - de saber o que existe para além dos limites de sua capacidade de percepção. Os ex-cegos de Saramago continuarão vivendo no inferno por não conseguirem construir com eficiência um paraíso artificial que satisfaça a sua incorrigível melancolia e a sua insuportável saudade de uma qualquer transcendência vivida ou sonhada, que é e será sempre, simultaneamente, a glória e a derrota de todos os visionários. 


\section{Referências Bibliográficas}

BACHELARD, Gaston. O céu azul. In: O ar e os sonbos: ensaio sobre a imaginação do movimento. São Paulo: Martins Fontes, 1990.

BARDI, Pietro Maria (Consultor). Pieter Bruegel. São Paulo: Abril Cultural, 1967. (Coleção Gênios da Pintura).

BAUDELAIRE, Charles. Les aveugles. In: As flores do mal. Trad. introd. e notas Ivan Junqueira. Rio de Janeiro: Nova Fronteira, 1985. (Edição bilíngüe)

- A modernidade de Baudelaire: textos inéditos selecionados por Teixeira Coelho. Rio de Janeiro: Paz e Terra, 1988.

BENJAMIN, Walter. Magia e técnica, arte e politica. São Paulo: Brasiliense, 1993.

. Charles Baudelaire: um lírico no auge do capitalismo. São Paulo: Brasiliense, 1989.

CALVINO, Ítalo. Visibilidade. In: Seis propostas para o próximo milênio. São Paulo: Companhia das Letras, 1993.

DERRIDA, Jacques. Mémoires d'aveugle. L'autoportrait et autres ruines. Paris: Réunion des Musées Nationaux, 1992.

GAGNEBIN, Jeanne Marie. Walter Benjamin ou a história aberta. In: BENJAMIN, Walter. Obras escolhidas, v. I - Magia e técnica, arte e política. São Paulo: Brasiliense, 1987.

GOMBRICH, E. H. Meditations on a hobby-borse. London: Phaidon, 1994.

. Art and illusion. A study in the psychology of pictorial representation.

London: Phaidon, 1968.

. "The sky is the limit": the vault of heaven and pictorial vision. In: The image and the eye. Further studies in the psichology of pictorial representation. Oxford: Phaidon, 1982.

HAGEN, Rose-Marie e Rainer. Pieter Bruegel, o Velho. Camponeses, loucos e demônios. Lisboa: Taschen, 1995.

HEFFERNAN, James. Museum of words. Chicago and London: The University of Chicago Press, 1993.

JAY, Martin. Scopic regimes of modernity. In: FOSTER, Hal (Ed.). Vision and visuality. Seattle: Bay Press, 1988. 
JAY, Martin. Downcast eyes. The denigration of vision in twentieth-century French thought. Berkeley, Los Angeles, London: The University of California Press, 1993.

KONERSMANN, Ralf. Magritte: la reproducción prohibida: sobre la visibilidad del pensamiento. Madrid: Siglo Veinteuno de España Editores, 1996.

KRAUSS, Rosalind. The optical unconscious. London, Cambridge, Massachusets: The Mit Press, 1992.

LEVIN, D.M. (Ed.). Modernity and the hegemony of vision. Berkeley: University of California Press, 1993.

MERLEAU-PONTY. O visível e o invisível. São Paulo: Abril Cultural, 1975.

MITCHELL, W. J. T. Iconology. Image, text, ideology. Chicago and London: The University of Chicago Press, 1987.

1994.

. Picture theory. Chicago and London: The University of Chicago Press,

NOVAES, Adauto (Org.). O olhar. São Paulo: Companhia das Letras, 1988.

SARAMAGO, José. Ensaio sobre a cegueira. São Paulo: Companhia das Letras, 1995.

. Manual de pintura e caligrafia. São Paulo: Companhia das Letras,1992.

WELLS, H. G. The country of the blind. In: Selected short stories. New York: Penguin Books, 1979. 


\section{Resumo}

Este ensaio procura discutir o conceito de modernidade de Charles Baudelaire através da análise comparada de seu poema "Os cegos" com a pintura de Pieter Bruegel "A parábola dos cegos", como introdução ao estudo comparado de textos de dois autores que refletem sobre a modernidade através da mesma temática: H. G. Wells e José Saramago.

\section{Abstract}

This essay tries to discuss Charles Baudelaire's concept of modernity through the comparative analysis of his poem "The Blind" with the painting of Pieter Bruegel "The Parable of the Blind", as an introduction to the comparative study of texts of two authors that think about modernity through the same topic: H.G. Wells and José Saramago. 